\title{
VEINTE AÑOS \\ DEL DEFENSOR DEL PUEBLO
}

\author{
ANTONIO ROVIRA VIÑAS \\ Profesor Titular de Derecho Constitucional \\ Universidad Autónoma de Madrid
}




\title{
VEINTE AÑOS DEL DEFENSOR DEL PUEBLO
}

\author{
POR \\ ANTONIO ROVIRA VIÑAS \\ Profesor Titular de Derecho Constitucional \\ Universidad Autónoma de Madrid
}

En 1990, al llegar al Defensor del Pueblo, me encontré con una institución a la que teóricamente no le había prestado excesiva atención y respecto de la cual muy pocos sabían bien para lo que servía, pero pronto comencé a transformarme en contagio con otros asesores en un proceso en el que cierta locura era cordura y empecé a darme cuenta que, el trabajo del Defensor, consistía fundamentalmente en dejar al descubierto el forro del Estado, despejando la mirada sobre los nimios acontecimientos que se producen tras la tribuna que lo sustenta y que como en el cuento de Anderssen, permite al niño ver desnudo al poder.

Qué sabríamos de los defectos del funcionamiento del Estado, si desde abajo no se hubiese narrado año tras año las exclamaciones y testimonios presenciales con las voces más profundas y con la fuerza que dan a la palabra aquellos que no hacen la historia, pero a los que inevitablemente ésta les ocurre. Si no hubiera estado allí, no sabría casi nada de la complejidad de las situaciones sociales, comprobando una vez más que la mejora de nuestras garantías y derechos, por no decir todas, han surgido de las perdidas y las crisis. Cuando las estructuras se rompen contra su propia historia y se convierten en casi nada, cuando la historia de nuevo titubea y en ocasiones zozobra y las ideologías se desvanecen, ofreciendo la sensación de que todo puede resbalar, cuando los juristas, cansados de pelearnos por notas a pie de página, nos extraviamos en una cierta incertidumbre, es entonces 
cuando organismos tan originales, presentes e indeterminados como el Defensor del Pueblo, se empiezan a cotizar más y, sin que nadie lo reconozca, va reuniendo las miradas en torno a él, porque, en cierta forma, el Defensor vive de las crisis, de lo que los demás hacen mal o no hacen. No es mala iniciativa comprobar con el Defensor cómo el poderoso, atareado en pergeñar su complejo temario, olvida y no ve lo que de esencial le parece superfluo

El Defensor es el que mejor escucha el ruido de la carcoma. Su función es profanar los santuarios y contar a los supervivientes las viejas y nuevas realidades. Sin embargo, si hojean las declaraciones o escuchan el murmullo del mundo del derecho y la política, siempre que lo secundario desplaza impertinentemente a lo primario, hay una cierta tendencia a ocultarlo o minimizarlo.

No obstante, mientras el poder sea contradictorio el Defensor tendrá sentido, incluso a pesar de todos los pesares, seguirá siendo, en el buen sentido, un poco subversivo y volteará la mirada y se encontrará con las personas para las que la Institución no es sólo una garantía, sino un medio para sobrevivir.

El trabajo del Defensor, con este halo de indeterminación y de ambigüedad que halaga, multiplica y atrae la atención de las gentes, renuncia con su obra a los fastos de lo inexplicable y se conforma con que ésta sea neta, evidente y correcta. Es el que desenreda la maraña de argumentos, oscuridades calculadas y neologismos vacuos para la inaccesibilidad y la espesura, frenando los excesos de poder y denunciando el desprecio de quienes niegan la existencia de los problemas e injusticias.

No busca ninguna originalidad deslumbrante, pronto sabemos lo que quiere decir y sabemos que de un modo u otro, lo repite año tras año, hasta el punto de que llegamos a pensar, equivocadamente, que podemos pasar sin él. El Defensor no tiene la obligación de veracidad, ni de neutralidad, aunque sí de independencia. Tampoco tiene la superstición de lo nuevo, ni debemos considerarle excesivamente dogmático en contra de sus presupuestos. La más clara acusación que podemos hacerle es que lo ve todo negro. Incluso cuando las formas de sus actuaciones son afirmativas su contenido es siempre negativo y este es su papel.

Es una institución difícil de definir y aún provoca una risa fácil por los excesos de su nombre, demasiado estruendoso, como aquel relato de Kafka, donde el mensajero del emperador no podrá llegar nunca a su meta porque la inmensidad artificial del propio imperio se 
lo impide, o por la misma razón por la que Aquiles no conseguirá dar alcance a la tortuga, de igual modo, tampoco el Defensor logrará realizar la imagen que provoca su nombre en las conciencias.

El Defensor del Pueblo, entendido literalmente, no es un medio para avanzar, sino un fin en sí mismo. El nombre tiene la gran ventaja de la proximidad y simplicidad, que lo diferencia de los otros organismos oficiales que resultan tan distantes y artificiales que provocan rechazo, incluso miedo. Aunque hay que tener cuidado, porque no hay esperpento sin un fondo solemne sobre el que destacarse. ¿Y qué mejor fondo y de mayor solemnidad que el nombre de Defensor del Pueblo?

Después de veinte años, aún no sabemos bien lo que es, aunque el saberlo no es imprescindible, incluso a veces, y más en esta clase de instituciones, en el saber, la teoria puede interponerse como un burócrata insaciable, un poco al modo de aquella parodia donde Cortázar da instrucciones para subir una escalera de forma tan detallada y teórica que los oyentes se quedan en la higiene de los manuales de uso sin lograr apenas ascender un peldaño. El Defensor, debe ser una institución material, dúctil que, envuelta en el Derecho, se sumerja en la sociedad.

Estoy convencido de que, fuera de algunos rudimentos teóricos, al Defensor se le conoce y comprende cuando se acude a él, enriqueciéndose con la experiencia lo que ya se sabe. De esta forma la teoría alcanza a tener un sentido y a mejorar la comprensión de lo que es $y$ lo que hace el Defensor por los ciudadanos. Y así, a pesar de los defectos de su ley reguladora, el Defensor del Pueblo ha cumplido dos décadas. Nadie podía imaginarse cuando fue creado que adquiriera tal importancia y que se mantuviera tan vivaz y alerta, nutrido de aspiraciones, escéptico, punzante, cortés, reposado y colérico, alegre y desesperado a la vez, dividido entre la avidez de la vida y el sentido de la responsabilidad.

La naturaleza del Defensor del Pueblo refleja con bastante exactitud la vieja contraposición romana entre auctoritas y potestas, distinción que cayó en desuso durante siglos, pero que resucita como categoría necesaria para definir y situar al ombudsman en el conjunto de las instituciones. La contraposición autoridad-potestad, la encontramos en la esencia misma de la constitución republicana romana, donde la potestad de los magistrados, que era la concreción de la majestad popular, estaba limitada por la autoridad senatorial.

Revestidos de autoridad estaban también los juristas, que con su saber prudencial asesoraban a los magistrados, jueces y particulares, 
y los augures, que mediante la observación de ciertos signos celestes, interpretaban la voluntad de los dioses y cuya opinión de autoridad se imponía a cualquier otra.

Este reparto de funciones entre la auctoritas de los augures y senadores y la potestas de los magistrados, o del pater familias, sirvió para establecer un sabio equilibrio. La potestas era delegable y territorial, la auctoritas era indelegable y personal. Con el inicio del Principado ese binomio fue sustancialmente alterado, hasta desparecer un siglo después, cuando se identificó la autoridad y la potestad en la persona del Emperador, situación heredada hasta nuestros días. La auctorítas no sólo puede definirse como el saber socialmente reconocido, sino la influencia que tiene aquel al que se reconoce ese saber. En términos generales, la autoridad es un estatus, un ámbito de actuación en función de su saber e influencia, de lo contrario, la potestad absorbe la autoridad, como ocurrió en la época de la inquisición y sigue ocurriendo en las dictaduras.

No obstante, para que el Defensor del Pueblo adquiera esta autoridad, este respeto social incluso político, esta confianza que da la sola presencia, es decir, para que alcance lo más alto, que como dice Borges, "es sencillamente ser admitido como una parte de la realidad innegable, como las piedras o los árboles", no solamente es necesario gozar de independencia y prestigio, es más importante incluso, que se gane el apoyo y reconocimiento social de la gente con sus actuaciones, que deben ser jurídicamente rigurosas y claramente fundamentadas, novedosas, avanzadas e imaginativas. La auctoritas se adquiere y mantiene con la independencia y rigor de los actos, no es una cualidad que una vez otorgada se mantenga. Por el contrario debe ser ganada y consolidada con la publicidad y divulgación de sus actuaciones efectivas y rigurosas. Por eso el ombudsman necesita de una cierta complicidad con los medios de comunicación, necesita que éstos divulguen el carácter de la institución y su trabajo y con él, la autoridad de su titular.

El ombudsman es necesario porque en las sociedades democráticas avanzadas cada día se necesitan mas instancias con autoridad que limiten y controlen esta tendencia omnicomprensiva del poder, que aunque constitucionalmente dividida, esta muy concentrada, $y$ ésta puede ser una de las razones para explicar la actualidad y su auge en el mundo.

Podemos admitir que las cosas estén mal, pero no que se niegue que lo están. A esta labor de evidenciar, de destapar y divulgar, puede contribuir en gran medida el Defensor, denunciando a los que 
niegan las evidencias, a los que hacen luz de gas con los problemas sociales, que disimulan lo obvio a base de desfigurarlo y cubrirlo y distraerlo. El Defensor puede contribuir en gran medida a destapar la verdad y construir un mínimo común acuerdo y una minima aceptación de la realidad palpable.

El Defensor del Pueblo es una institución que cuesta definir, es distinta a las demás, rara, incluso contradictoria con el imperio de la ley y la distribución territorial e institucional del poder en el Estado de Derecho. Una institución que sin poder, tiene por finalidades controlar a los poderes legitimados democráticamente $y$, en nuestro caso, incluso al propio parlamento y que, además, lo hace efectivamente sobre la base de la autoridad, persuasión y al coste político que tiene para los órganos e instituciones fiscalizados, ser denunciados públicamente por el Defensor y asi el Ombudsman, sin poder jurídico, puede condicionar la voluntad de los poderes soberanos.

El Defensor del Pueblo es un ombudsman cuyas decisiones (recomendaciones, admoniciones, reproches, informes) no vinculan a sus destinatarios, pero adquieren efectividad en función de los argumentos jurídicos en los que se fundamentan. Es una garantía jurídica pero diferente, sin poder, ni competencias para anular actos o modificar situaciones, tan solo dispone de atribuciones para conocer las deficiencias y darlas a conocer a los otros poderes del Estado y a la sociedad. Esta naturaleza es lo común a todo ombudsman, lo que permanece en el cambio, su esencia.

En este sentido una queja no es más que una petición que pone en conocimiento $y$ normalmente solicita la modificación de una conducta. Peticiones y quejas que pueden dirigirse a cualquier órgano o institución y cuya naturaleza es dual, susceptible de ser utilizada tanto para satisfacer intereses particulares como necesidades generales, en definitiva, un derecho de participación política. Generalmente la petición tiene connotaciones graciables y la queja de exigencia, pero no siempre es así.

Si buscamos su origen, tenemos que detenernos en Suecia, donde surge la figura moderna del ombudsman y donde se perfecciona en sus rasgos más esenciales. Aunque podríamos remontarnos a otros antecedentes históricos más cercanos geográficamente, como los del Justicia de Aragón o del Sindic de Greuges de Catalunya.

La palabra sueca "ombudsman", se refiere a una persona que actúa como vocero o representante, y cuya tarea es cuidar los intereses de otra, es decir, aquella que recibe e investiga las quejas de los 
ciudadanos contra los actos injustos del gobierno. El Ombudsman debe ser una persona que se ocupa de las quejas del público y que dispone de capacidad bastante para investigar y denunciar las actuaciones lesivas, aunque no el poder para resolverlas.

El primer antecedente moderno de una institución así, lo encontramos en 1713 en la figura denominada Procurador Supremo, el cual ejercía una vigilancia general para asegurar el cumplimiento de las leyes y reglamentos y la actividad de los servidores públicos.

Durante la conocida como Era de Libertad que siguió a la muerte del Rey Carlos en 1718, todo el poder político fue asumido por el Parlamento sueco, RiKsdag, y el Canciller de Justicia del rey pasa a ser considerado un comisionado o representante del parlamento, que lo elige por primera vez en 1766. No obstante, en 1809, poco después de ser destronado, se aprobó una nueva constitución basada en un equilibrio de poderes entre el Rey y el RiKsgad y que regulaba de una forma bastante minuciosa los requisitos prerrogativas y funciones del Justitieombudsman (JO).

Éste debía ser una persona capaz, imparcial, versada en derecho $y$ cón experiencia como juez, que disponía de amplias facultades de intervención sobre la Administración Real y de Justicia. Era elegido por el Riksdag indirectamente, a través de una comisión constituida al efecto, comisión cuya composición era cuidadosamente estudiada, para evitar interferencias de los partidos y ante la que debía presentar anualmente el informe de su actividad fiscalizadora. Era un cargo incompatible con cualquier otro puesto, y el control de su actividad lo realizaba fundamentalmente la Comisión del Parlamento. No obstante, desde que el primer Ombudsman fue elegido en 1810, la figura Sueca ha evolucionado mucho, acusando una cierta decadencia. La organización y los métodos de trabajo han sido reformados profundamente debido al desarrollo de la Administración y los cambios en la sociedad. El más notable que ha experimentado ha sido el incremento gradual del numero de titulares, el aumento del número de ombudsman se justificó por el aumento del número de quejas. Es decir, una institución única pero compartida por tres ombudsman, cada una de las cuales ostenta el título Justitieombudsman. Uno se encarga de las quejas de la Administración de justicia, el ejército y la policía; el segundo atiende a los asuntos sociales, medios de comunicación y educación, $y$ al tercero le corresponde conocer de las quejas que no atienden los otros dos.

Finalmente, desde la Constitución Sueca de 1975 actúan conjuntamente cuatro ombudsman, que ejercen sus funciones coordina- 
damente en una única institución, distribuyéndose las competencias por razón de la materia. Posiblemente, esta pluralidad de titulares ha afectado a la claridad, proximidad y conocimiento popular de la institución. El aumento de las quejas y de los ámbitos de control, sin duda justifican un aumento de los medios y del tamaño de la oficina, pero no necesariamente del numero de titulares. Posiblemente sea esta pluralidad la que ha afectado a su imagen e influencia como modelo y referente en el mundo. Además, en Suecia actúan otros ombudsman que cumplen también funciones de protección a la ciudadanía, como el ombudsman de los consumidores, de la libertad económica o de la prensa. La confusión resulta, por tanto, inevitable.

A partir de entonces, su reconocimiento, se ha extendido por los cuatro continentes adoptando las más diversas, incluso curiosas formas ya que su naturaleza, flexible e indeterminada, permite una gran capacidad de adaptación y flexibilidad incorporándose a los más variados sistemas jurídicos y estructuras. De todo ello tenemos ejemplos muy cercanos. En Latinoamérica la figura del Ombudsman nacional se ha introducido en las constituciones de países tan cercanos como Guatemala, el Salvador, Honduras, Costa Rica, Colombia, Bolivia, Perú, Venezuela, Panamá, Nicaragua, Argentina o Paraguay. En cada uno de ellos con la forma que determinan sus peculiaridades, adaptándose a las tradiciones, a la historia y necesidades con diferentes denominaciones (Procuraduría de Derechos Humanos, Defensoría de los Habitantes o Defensor del Pueblo). En definitiva, todos diferentes porque todos somos hijos nuestra memoria y el olvido es el desierto, pero todos a su vez con una naturaleza común que nos diferencia de los demás.

La aparición tan generalizada de los ombudsman se explica a tenor de la propia naturaleza de los derechos fundamentales y sus garantías, que si no avanzan desaparecen y los ombudsman son necesarios porque los ciudadano, cada día en mayor medida, se ven obligados a abrirse paso ante un bosque no sólo de leyes, sino también de disposiciones nacionales, e internacionales, complejas y en algunos casos alejadas del fin que las justificó. Cada vez más en nuestras sociedades se elevan nuevas barreras y se abren fosos entre tales quejas y la solución efectiva de las mismas, entre las proclamaciones formales y la vigencia efectiva de los derechos, porque estas relaciones están sustentadas sobre una estructura compleja, dispersa e indeterminada, que con excesiva frecuencia ignora en sus actuaciones lo que es la coordinación y cuyas decisiones llegan al ciudadano por las vías más variadas, en un lenguaje no fácilmente comprensible y casi siempre con un carácter imperativo difícilmente discutible para quien no 
sea un especialista en leyes o no tenga los medios económicos suficientes.

Pues bien, estas realidades exigen urgentemente nuevas legalidades renovando incluso la idea que tenemos del Derecho, que cada vez tendrá un carácter más internacional y, lo que es más importante y difícil, nuevos comportamientos. El funcionamiento tradicional del Estado y su administración, que no es ideal pero sí necesario, ya sólo sirve para decirnos lo que es evidente. La política tiene sentido si inventa nuevas perspectivas. Lo cierto es que ante estos cambios el ciudadano se encuentra cada vez más desorientado $y$, en muchas ocasiones, no sabe ni siquiera cuál es la administración competente para contestar su queja. Cada vez resulta más difícil saber quién tiene la competencia y el poder para intervenir, regular y decidir, cada vez resulta más oscuro saber a quién tenemos que dirigirnos.

¿Cuál es entonces la tarea esencial que este progreso y estas circunstancias de cambios vertiginosos exigen al Defensor del Pueblo? Sencillamente, la de procurar la solución de los problemas que las quejas presentan de una forma rápida y efectiva, evitando que se tenga que acudir a las vías de recurso o jurisdiccionales que normalmente son más costosas y la de contribuir a adaptar las leyes, los talantes y comportamientos para que aumente la claridad y la cercanía, para que no se profundice más la fractura entre poder y sociedad.

Pues bien, la institución del ombudsman, con su naturaleza novedosa y especial que tanto cuesta definir jurídicamente, puede resultar útil en este novedoso proceso transnacional y si ya resultaba desde hace tiempo conveniente su reconocimiento, más lo será en el futuro, cuando se exigirá al poder democrático resolver conflictos y problemas de un mundo en proceso de transformaciones rápidas, complejas y profundas.

Resulta necesario, en este clima de vertiginoso cambio, reconocer nuevas instituciones, que sin sustituir a las tradicionales las complementen y perfeccionen en el camino que justifica a todo Estado de Derecho, cual es la realización efectiva de los Derechos Humanos, suponiendo que exista algún derecho que no lo sea. Derechos que no han caído del cielo, ni se han dado todos de una vez. Que son fruto de conquistas parciales logradas siempre cuesta arriba, frente a la pendiente.

Estamos hablando de una institución que sin sustituir ni colisionar, ni mucho menos suplantar a las instituciones democráticas, tradicionales, sin pertenecer ni asumir competencias de los tres clásicos 
poderes del Estado, intenta defender y acercar a los ciudadanos al funcionamiento del sistema de una forma más rápida y efectiva, a tenor de las características de flexibilidad, informalidad, inmediatez, agilidad que le caracterizan.

El Defensor del Pueblo no puede juzgar, ni legislar, ni gobernar o ejecutar. Su función consiste en denunciar cualquier actuación de los poderes del Estado contraria a los derechos fundamentales, en general al ordenamiento jurídico y para ello dispone de una serie de atribuciones, entre ellas, recurrir al Tribunal Constitucional, formular recomendaciones, sugerencias, advertencias y recordatorios legales a las Administraciones Públicas y denunciar los comportamientos irregulares de éstas ante el superior jerárquico, incluso ante las Cortes Generales y ante la opinión publica, intentando a su vez colaborar con todos para lograr el mejor funcionamiento del Estado de Derecho.

Así, el DP controla las anomalías y las actuaciones irregulares o con efectos perniciosos del Poder ejecutivo y dispone para ello de amplios poderes de acceso e investigación de cualquier actuación o resolución administrativa, desde los ministros hasta el más escondido funcionario de cualquier administración pública, local, autonómica, central o institucional, también lo que la Ley Orgánica del Defensor del Pueblo denomina «agentes», empresas públicas o aquellas empresas privadas que sean objeto de concesiones de un cierto servicio público. Puede realizar recomendaciones o sugerencias para que se modifiquen las conductas lesivas a los derechos o se mejoren sus efectos.

También controla al Poder legislativo del que es Comisionado, al tener la posibilidad de presentar recurso de inconstitucionalidad, fundamentalmente por violación de los derechos fundamentales contra las leyes, disposiciones o actos con fuerza de ley del Estado, las comunidades autónomas, tratados internacionales, etc. y recurso de amparo ante los actos sin valor de ley de los mismos poderes. Finalmente, el Defensor también controla el correcto funcionamiento del poder judicial a través del Fiscal General del Estado y el Consejo General del Poder Judicial, dirigiéndose a éstos para que se adopten las medidas necesarias y mejorar así su funcionamiento. De todo ello debe dar cuenta anualmente a las Cortes Generales mediante un informe y las correspondientes comparecencias ante la Comisión Mixta.

Con estas potencialidades el Defensor del Pueblo no es, como maliciosamente se dice, un adorno. Sus atribuciones son importantes y sobre todo adecuadas para servir de garantía a esta sociedad que avanza a la velocidad de la luz. Es una garantía técnico-jurídica y como 
tal actúa. No es un órgano benéfico, realiza un control jurídico, sus actuaciones están fundamentadas en la aplicación e interpretación del Derecho, en razones jurídicas. Pero teniendo en cuenta que lo jurídico no puede reducirse ya al estudio dogmático de su gramática, que coincide con la falsa excelsitud de quienes ponen los ojos en blanco cuando hablan de "concepto" de "ley" o de "principios" y no están dispuestos a dejarse contaminar con historias, casos o subjetividades. El $D P$ tiene facultades y aptitudes para desarrollar esta labor de adecuación, de adaptación del Derecho.

Lo realmente sorprendente, es que, en menos de un siglo, el ombudsman ha pasado de ser una figura nórdica casi desconocida, a disponer de un cierto protagonismo y esta popularidad está sorprendiendo a todos. En ocasiones parece que necesitamos algo nuevo sin saber muy bien, porqué y para qué. Lo que resulta ya evidente es la insuficiencia de las garantías tradicionales, demasiado rígidas para enfrentarse con éxito a los grandes retos globales.

Uno de estos retos, no sé si el mayor, es la trivialización de los Derechos Humanos y de sus garantías y entre ellas el propio ombudsman, es decir, el uso abusivo superficial de éstas para legitimar las peores opciones políticas, o su banalización al instrumentalizarlos con el objetivo de hacer "luz de gas" sobre los problemas sociales.

La trivialización de los Derechos Humanos y el emborronamiento de garantías como el ombudsman se produce cuando se da un exceso de retórica sentimental que anula su naturaleza racional, práctica, positiva, jurídica, transformándolos en principios morales, máximas o consignas, catálogos o mandamientos, sin poder de vinculación. Pues bien, instituciones como el Defensor del Pueblo pueden resultar apropiadas para combatir la simulación y trivialización que permiten que los derechos fundamentales sean compatibles con cualquier forma de servidumbre.

Otra "cuesta arriba" que tendremos que salvar es el fanatismo integrista. El movimiento en una dirección provoca el contrario. La globalización provoca como reacción el auge del localismo fundamentalista, la exacerbación de un sentimiento colectivo gregario, sea de raza, de clase, de religión o de grupo, incluso el fanatismo de los buenos sentimientos, "tengo tan buenos sentimientos que mato por ellos». El fundamentalismo consiste en grupos sumisos al mandato carismático de un jefe, o de un sentimiento o de ambos a la vez, en los que es más fácil encontrar hombres dispuestos a morir que a vivir dignamente en libertad. $Y$ esto nunca ha estado tan claro como ahora. 
El integrismo llama a las puertas del siglo $X X I$ como un virus muy contagioso que traspasa todos los límites. Los antiguos vocablos asesinato, masacre, genocidio no sirven para calificar los horrores de los fundamentalistas actuales y futuros. Los crímenes del fanatismo actual, su frialdad, su constancia, su falta de objetivos son inéditos. No logran sus victorias, en el campo de batalla, ejército frente a ejército, sino que sus tropas operan sobre niños y adultos indefensos. Los civiles ya no son, como en las guerras tradicionales, las víctimas accidentales sino que se convierten en los objetivos principales. Las mujeres y los niños son los primeros en morir o sufrir. Los atentados impactan por su intensidad no por su cantidad. El fanatismo hace alarde de los crímenes, es un artesano del terror.

Antes el criminal intentaba esconderse, disimular y negar, el fundamentalista presume de la crueldad, del sufrimiento, porque la finalidad de sus crímenes es el impacto.

¿Cómo podemos combatir estos santuarios localistas? Quizá actuando contra la terminología fundamentalista y aplicando la ley penal. Pero también ayudando y educando a las personas en los valores de tolerancia, ayudando a superar el miedo a la libertad. El fanatismo crece con la exclusión, con el aislamiento, con las desigualdades y la ignorancia. Por eso hay que intentar abrir las sociedades y grupos donde actúan estos fanáticos de la pureza para denunciar y superar esta tendencia hacia lo gregario $y$ excluyente imponiendo la tolerancia.

Pero también la palabra tolerancia se nos escapa de las manos, se banaliza y corre el riesgo de convertirse en un término vacío. No se puede tolerar la guerra, la injusticia o el crimen. Tolerar no consiste en ponen la otra mejilla, no es resignación, ni caridad, ni implica debilidad, transigir o callar, ni tiene nada que ver con el acto de generosa condescendencia de quienes creen estar en posesión de la verdad, ni con la actitud tradicional y prepotente del misericordioso, ni con los integristas que asumen el papel de salvadores para liberar a toda costa al hombre, la nación o el Estado del mal y del pecado, aunque toleren en ocasiones algunas impurezas y deslices.

La tolerancia no pertenece al orden moral. Al contrario, es un instrumento de lucha contra el arraigo profundo que todavía conservan los fanatismos, integrismos, fervores y pasiones colectivas o individuales, también de los movimientos espirituales de las sectas que encuentran placer en el sacrificio. Los héroes y los mártires en el fondo son lo mismo, los dos creen groseramente que con el sacrificio y la sangre puede demostrarse una verdad. 
Tolerar es respetar los Derechos del otro, no sus tonterias, es una forma de vivir y de concebir la vida. Es un talante, una forma de ver y tratar como propio lo diferente $y$ al diferente $y$ un principio necesario para garantizar la convivencia pacífica con aquello que no nos gusta, porque lo que gusta no necesita ser tolerado. La tolerancia no es buena ni mala, ni verdadera ni falsa, es simplemente necesaria para nosotros mismos. Si somos tolerantes es porque buscamos lo más conveniente para nosotros mismos, no porque debamos serlo en favor de no sé qué principio trascendental.

La tolerancia pertenece, por tanto, al orden social y político y es necesaria para defender los derechos de cada uno y para afrontar los cambios que se suceden, fronteras y culturas cada vez más cercanas, dúctiles y porosas que hacen la diferencia entre lo interior y exterior casuística. Cambios que requieren y requerirán aún más en el futuro nuevas actitudes para superar, por ejemplo, la tendencia de muchos a defender con uñas y dientes su cómoda fortaleza frente a los mendigos, inmigrantes, refugiados o asilados.

La tolerancia se basa así en la igualdad de Derechos, en la idea de que la inteligencia y la tontería están muy repartidas en este mundo y que este reparto no depende del lugar, el color o el dinero. En la idea de que toda teoría, experimento u opinión, por muy acertada que sea, tan sólo supone una aproximación. No cree en el hombre puro, prefiere el mestizaje como prefiere el diálogo, pero no el diálogo pedagógico que te dice lo que tienes que hacer, sino crítico en defensa de la libertad de cada uno a ser, pensar y vivir como quiera, con respeto a los demás, sin segregar al otro por su condición u opinión diferente. En definitiva, la tolerancia exige reflexión ante la diferencia, que perturba la tranquilidad de nuestra "madriguera», y exige también fomentar la diferencia como necesidad personal, social y política.

En la labor de divulgación de los principios y valores constitucionales, de educación y formación en la cultura democrática, también puede contribuir la proximidad, flexibilidad $y$, sobre todo, autoridad del ombudsman, denunciando las actuaciones rígidas e intolerantes de las administraciones, ya que sus actuaciones no solamente están basadas en la legalidad, sino también en la oportunidad, efectividad e incluso conveniencia. 